\title{
Expression and purification of African Swine Fever virus p72 trimers as subunit vaccine candidate
}

\author{
Kaiwen Menga*, Yueping Zhanga*, Wenzhuang Zhu ${ }^{\mathrm{a}}$, Ye Xiang ${ }^{\mathrm{b}}$, Geng Menga ${ }^{\mathrm{a}}$ \\ a College of Veterinary Medicine, China Agricultural University, 100193, Beijing, China \\ $b$ School of Medicine, Tsinghua University, 100084, Beijing, China \\ * These authors contribute equally to this work. \\ $\dagger$ Corresponding author. \\ E-mail address: mg@cau.edu.cn
}

The authors have withdrawn this manuscript because the result is invalid. We intend to revise it on our technical approach and interpretation of the results. The authors do not wish for this manuscript to be cited as a reference for this project. Please contact the corresponding author if you have any questions. 